\begin{tabular}{cc}
\hline TAP CHÍ KHOA HỌC ĐẠI HỌC TÂN TRÀO \\
http://tckh.daihoctantrao.edu.vn/
\end{tabular}

\title{
Nghiên cứu trồng thử nghiệm giống dưa vàng Kim Cô Nương tại tỉnh Tuyên Quang
}

\author{
Nguyễn Thị Minh Huẹ $\hat{a}^{a^{*}}$, Trịnh Phuoong Ngọc ${ }^{a}$, Trần Thị Bình ${ }^{a}$ \\ ${ }^{a}$ Truò̀ng Đại học Tân Trào \\ *Email:minhhuetkt@gmail.com
}

\section{Thông tin bài viết}

Ngày nhận bài:

16/11/2018

Ngày duyệt đăng:

$10 / 12 / 2018$

\section{Tù khoá:}

Dưa Kim Cô Nuong; Tuyên Quang; đánh giá sinh trương và phát triển; hiệu quả kinh tế.

\begin{abstract}
Tóm tắt
Ở nước ta, giống dưa Kim Cô Nương đã được áp dụng trồng trên đất trồng cây ngắn ngày tại một số tỉnh ở miền Bắc, đem lại hiệu quả cao hơn trồng lúa và các cây trồng khác. Dưa vàng Kim Cô Nương có tiềm năng phát triển tốt ở Tuyên Quang, tuy nhiên hiện nay người dân chưa biết đến và loại dưa này chưa được đưa vào sản xuất. Trên cơ sở đó, giống dưa Kim Cô Nương được nghiên cứu trồng thử nghiệm trên đất trồng lúa tại Trung tâm Thực nghiệm, thực hành và Chuyển giao Khoa học công nghệ, trường Đại học Tân Trào, tỉnh Tuyên Quang. Kết quả bước đầu cho thấy cây sinh trưởng tốt, đem lại năng suất cao hơn khoảng 1,9-2,3 tạ, hiệu quả kinh tế cao hơn 61,4 triệu đồng/ha so với giống đối chứng là dưa lê Thanh Đường hiện đang trồng tại địa phương trên cùng một đơn vị diện tích và thời gian.
\end{abstract}

\section{1. Đặt vấn đề}

Giống dưa vàng Kim Cô Nương thuộc chi Citrullus, loài Lanatus, thuộc họ bầu bí là giống dưa chất lượng cao, thuộc giống lai F1 thế hệ mới, có nguồn gốc từ Thái Lan. Giống có khả năng sinh trưởng, phát triển khỏe, thích ứng rộng. Miền Nam trồng được quanh năm, miền Bắc trồng vụ xuân và hè thu; thời gian sinh trưởng 58-62 ngày (tùy thời vụ), thời gian từ ra hoa đến thu hoạch 28-35 ngày; quả có hình tròn hơi oval, vỏ trơn, khi chín màu vàng kim, trái đồng đều, trọng lượng quả 1,1-2 kg. Thịt trái ăn rất ngon, giòn và ngọt, thơm.

Hiện nay, cơ cấu giống cây trồng ngắn ngày trong sản xuất nông nghiệp của tỉnh Tuyên Quang để sử dụng trên đất 3 vụ, đất 2 vụ hoặc đất trồng màu vẫn còn nhiều hạn chế. Các cây trồng cạn ngắn ngày chủ yếu vẫn là ngô, khoai, đậu, lạc, rau màu. Việc tìm hiểu, bổ sung các giống cây trồng có thời gian sinh trưởng ngắn, thích ứng rộng, dễ áp dụng vào các vụ, chủ động trong sản xuất, hơn nữa phải đem lại hiệu quả là điều mà mọi người dân mong muốn. Những năm gần đây, tại một số tỉnh ở miền Bắc như Lạng Sơn, Hải Dương, Hải Phòng đã áp dụng trồng giống dưa Kim Cô Nương trên đất trồng cây ngắn ngày, đem lại hiệu quả cao hơn trồng lúa và các cây trồng khác. Dưa vàng Kim Cô Nương có thể phát triển tốt ở điều kiện nhiệt độ $25-30^{\circ} \mathrm{C}$, ẩm độ không khí 80-85\%, có tiềm năng trồng thuận lợi ở Tuyên Quang. Trên địa bàn tỉnh Tuyên Quang hiện nay, người dân vẫn chưa biết đến và chưa đưa loại dưa này vào sản xuất. Trên cơ sở đó, giống dưa vàng Kim Cô Nương được nghiên cứu trồng thử nghiệm trên đất trồng lúa, làm cơ sở cho quá trình đưa loại dưa này vào trồng đại trà trên địa bàn tỉnh, góp phần nâng cao năng suất, thu nhập và cải thiện đời sống cho người dân địa phương.

\section{Nội dung và phương pháp nghiên cứu}

\subsection{Vật liệu nghiên cúu}

- Vật liệu nghiên cứu là giống dưa vàng Kim Cô Nương 
- Phạm vi nghiên cứu: Khả năng sinh trưởng phát triển; khả năng chống chịu sâu bệnh hại chính, năng suất, hiệu quả kinh tế của giống dưa vàng Kim Cô Nương.

\section{2. Địa điểm và thò̀i gian nghiên cúu}

- Dưa Kim Cô Nương được trồng với quy mô thử nghiệm $2.200 \mathrm{~m}^{2}$, trồng theo băng, trong vụ xuân 2017. Nguồn giống dưa được mua tại Học viện Nông Nghiệp Việt Nam và áp dụng quy trình trồng theo hướng dẫn kỹ thuật của giống dưa Kim Cô Nương.

- Địa điểm trồng: Trên đất 2 vụ lúa tại Trung tâm Thực nghiệm thực hành và $\mathrm{CGKHCN}$, trường Đại học Tân Trào.

\subsection{Nội dung nghiên cứu}

- Đánh giá về sinh truởng, phát triển của giống dua vàng Kim Cô Nuơng trồng tại Tuyên Quang:

+ Đánh giá các giai đoạn sinh trưởng phát triển

+ Đánh giá về sự sinh trưởng

- Đánh giá khả năng chống chịu với một số loại sâu bệnh hại chính

- Đánh giá đặc điểm của quả và năng suất

+ Đặc điểm của quả

+ Năng suất lý thuyết

+ Năng suất thực thu

- Đánh giá hiệu quả kinh tế.

\subsection{Các chỉ tiêu và phương pháp theo dõi}

Áp dụng theo quy chuẩn Quốc gia (Quy chuẩn Việt Nam 01-91:2012/Bộ Nông nghiệp phát triển nông thôn)

\section{* Chỉ tiêu về các giai đoạn sinh trương phát triển}

+ Ngày gieo: Ngày bắt đầu gieo hạt.

+ Ngày mọc: Ngày có trên $50 \%$ số cây có lá mầm lên khỏi mặt đất

+ Ngày ra hoa: Ngày có trên $50 \%$ số cây có hoa nở

+ Ngày chín thu hoạch: Ngày có trên $80 \%$ quả có màu vàng đặc trưng.

+ Tổng thời gian sinh trưởng, phát triển (ngày): Tính từ khi gieo đến khi chín thu hoạch.

\section{* Chỉ tiêu về sụ sinh trưởng phát triển}

+ Chiều dài thân chính $(\mathrm{cm})$ : Đo từ gốc đến đỉnh của thân chính

+ Khả năng phân nhánh (nhánh/cây): Đếm số nhánh trên thân chính.

* Chỉ tiêu khả năng chống chịu sâu bệnh hại chính
- Chống chịu rệp

- Chống chịu bọ trĩ

- Chống chịu bọ dưa

- Chống chịu bệnh héo xanh

- Chống chịu bệnh thối nhũn

- Chống chịu bệnh thán thư

Tỉ lệ bệnh $(\%)=(\Sigma$ Số cây bị nhiễm bệnh $/ \Sigma$ Số cây theo dõi) x 100

Thời gian điều tra: Tiến hành định kì 7 ngày điều tra một lần.

* Chỉ tiêu đặc điểm về quả và năng suất

- Đặc điểm về quả:

+ Số quả/cây (quả): Tổng số quả thu hoạch/tổng số cây theo dõi

+ Khối lượng quả $(\mathrm{kg})$ : Tính khối lượng trung bình quả của các cây theo dõi.

+ Đánh giá đặc điểm: Hình dạng quả, màu sắc quả, độ Brix, hương thơm

- Năng suất:

+ Năng suất lý thuyết (tấn/ha) = năng suất TB/cây (kg) x mật độ/ha x $10^{-3}$

+ Năng suất thực thu (tấn/ha): Năng suất thu được trên toàn bộ diện tích, cân rồi quy đổi ra (tấn/ha).

- Các chỉ tiêu về đặc điểm của quả được đánh giá bằng các giác quan; đánh giá độ Brix được đo bằng máy đo độ Brix. Đánh giá ở giai đoạn chín thu hoạch.

\section{* Hiệu quả kinh tế (dồng/ha)}

- Tổng chi: Tính toàn bộ tổng chi cho diện tích trồng thử nghiệm bao gồm giống, vật tư, công lao động, khấu hao dụng cụ.

- Tổng thu: Toàn bộ sản phẩm trên diện tích trồng thử nghiệm nhân với giá bán trên thị trường tại thời điểm, quy đổi ra tổng thu/ha

- Hiệu quả kinh tế $=$ Tổng thu - tổng chi

(Từ kết quả trồng thử nghiệm quy đổi ra ha)

\section{Kết quả và thảo luận}

Bảng 1. Thời gian sinh trưởng, phát triển của dưa vàng Kim Cô Nương

\begin{tabular}{|c|c|c|c|}
\hline \multicolumn{2}{|c|}{ Chì tiêu } & Dưa vàng Kim Cô Nương & Dura lê Thanh Dương \\
\hline \multicolumn{2}{|c|}{ Ngà̀y gieo } & $7 / 2 / 2017$ & $7 / 2 / 2017$ \\
\hline \multirow{4}{*}{$\begin{array}{c}\text { Tìr gieo đên } \\
\text { (Ngày) }\end{array}$} & Mọc & 6 & 5 \\
\cline { 2 - 4 } & Trồng & 16 & 16 \\
\cline { 2 - 4 } & Phàn nhánh & 27 & 25 \\
\cline { 2 - 4 } & Ra hoa & 56 & 50 \\
\cline { 2 - 4 } & Chin thu hoạch & 85 & 79 \\
\hline
\end{tabular}


Kết quả bảng 1 cho thấy, giống dưa vàng Kim Cô Nương gieo hạt ngày 7/2/2017 cùng với giống đối chứng dưa lê Thanh Đường. Từ gieo đến mọc là 6 ngày, từ mọc đến trồng là 16 ngày. Thời gian từ gieo đến phân nhánh của giống dưa Kim Cô Nương là 27 ngày, chậm hơn đối chứng 2 ngày. Từ gieo đến ra hoa là 56 ngày, chậm hơn đối chứng 6 ngày. Tổng thời giang sinh trưởng phát triển của giống dưa vàng Kim Cô Nương là 85 ngày, dài hơn đối chứng 6 ngày.

Bảng 2. Sự sinh trưởng phát triển của giống dưa

\begin{tabular}{|c|c|c|c|}
\hline \multicolumn{2}{|r|}{ Chì tiêu } & Dưa vàng Kim Cô Nương & Dưa lê Thanh Đrường \\
\hline \multicolumn{2}{|r|}{ Tỷ lệ moc (\%) } & 79,3 & 82,5 \\
\hline \multirow{4}{*}{$\begin{array}{l}\text { Chiề } \\
\text { ư tâi } \\
\text { thân }\end{array}$} & Giai đoạn trò̀ng (cm) & 11,6 & 8,2 \\
\hline & Giai đoạn phân nhánh (cm) & 35,4 & 29,1 \\
\hline & Giai đoạn ra hoa $(\mathrm{cm})$ & 93,5 & 84,7 \\
\hline & Giai đoạn chín $(\mathrm{cm})$ & 112,2 & 97,3 \\
\hline \multicolumn{2}{|c|}{ Số nhính/cây (nhánh) } & 4,6 & 5,1 \\
\hline \multicolumn{2}{|c|}{ Số hoa/cây (hoa) } & 6,4 & 8,7 \\
\hline
\end{tabular}

Về tỷ lệ mọc: Giống dưa vàng Kim Cô Nương có tỷ lệ mọc đạt 79,3\%, thấp hơn đối chứng 3,2\% (trong điều kiện nhiệt độ thấp nhất từ $12^{\circ} \mathrm{C}-14^{\circ} \mathrm{C}$, ẩm độ không khí từ $47 \%-50 \%$ đều không thuận lợi cho giai đoạn nẩy mầm).

Chiều dài thân: Giai đoạn trồng, giống dưa vàng Kim Cô Nương có chiều dài thân $11,6 \mathrm{~cm}$, hơn đối chứng $3,4 \mathrm{~cm}$. Giai đoạn phân nhánh và ra hoa đều có chiều dài thân hơn đối chứng. Giai đoạn chín thu hoạch có chiều dài tối đa, trung bình là $112,2 \mathrm{~cm}$ và hơn đối chứng 14,9 cm. Qua đó cho thấy giống dưa vàng Kim Cô Nương có chiều dài thân ở các giai đoạn đều hơn đối chứng, vì vậy cần chú ý kỹ thuật bấm ngọn để hạn chế sinh trưởng của thân.

Số nhánh/cây: Giống dưa vàng Kim Cô Nương có số nhánh trung bình là 4,6 nhánh, thấp hơn đối chứng không nhiều $(0,5$ nhánh). Nhưng cần chú ý cắt bỏ nhánh không để quả để tập trung dinh dưỡng tạo quả.

Số hoa/cây: Giống dưa vàng Kim Cô Nương có số hoa/cây trung bình là 6,4 hoa, ít hơn đối chứng 2,3 hoa. Qua theo dõi số hoa/cây, cần phải chủ động ngắt bỏ bớt hoa, chỉ để 2 đến 3 hoa ở vị trí cho quả tốt; sau khi đậu quả lại tỉa bớt quả, để 1quả/cây.

Bảng 3. Chỉ tiêu về chống chịu sâu, bệnh hại

\begin{tabular}{|c|c|c|c|}
\hline \multicolumn{2}{|l|}{ Chỉ tiêu } & Dưa vàng Kim Cô Nương & Dưa lê Thanh Đường \\
\hline \multirow{3}{*}{ Sâu hại } & Bo trĩ (\%) & 5,4 & 6,7 \\
\hline & Bọ dua (\%) & 4,2 & 4,6 \\
\hline & Rệp (\%) & 2,5 & 2,2 \\
\hline \multirow{3}{*}{ Bệnh $h a ̣ i$} & Héo xanh (\%) & 3,8 & 3,1 \\
\hline & Thối nhữ (\%) & 9,7 & 6,1 \\
\hline & Thán thư (\%) & 5,5 & 4,7 \\
\hline
\end{tabular}

Mỗi giống cây trồng đều có khả năng chống chịu sâu bệnh khác nhau, giống có khả năng chống chịu tốt đó chính là ưu điểm của giống. Kết quả theo dõi các chỉ tiêu về chống chịu sâu, bệnh hại (bảng 3) cho thấy:

Sâu hại: Sâu hại dưa chủ yếu là bọ trĩ, bọ dưa, rệp. Trong đó bọ trĩ hại là 5,4\%, thấp hơn đối chứng $1,3 \%$, rệp và bọ dưa bị hại 2,5-4,2 và tương đương đối chứng.

Bệnh hại: Bệnh hại chủ yếu là héo xanh, thối nhũn, thán thư. Trong đó bệnh thối nhũn bị hại nhiều nhất $9,7 \%$, cao hơn đối chứng $3,6 \%$, bệnh héo xanh và bệnh thán thư hại 3,8\% đến 5,5\% tương đương đối chứng.

Qua theo dõi cho thấy, nhìn chung giống dưa vàng Kim Cô Nương có khả năng chống chịu sâu bệnh hại chính không hơn đối chứng. Vì vậy cần có biện pháp chủ động phòng trừ tốt, nhất là bệnh thối nhũn, bệnh hại nhiều trong điều kiện nắng mưa xen kẽ, chân đất cát pha.

\section{Bảng 4. Chỉ tiêu về các yếu tố cấu thành năng suất và năng suất}

\begin{tabular}{|c|c|c|}
\hline Chi tiêu & Dưa vàng Kim Cô Nương & Dưa lê Thanh Đường \\
\hline Số hoa/cây (hoa) & 4,7 & 6,9 \\
\hline Số quà/cây (quà) & 1,2 & 4,3 \\
\hline Khối lượng quà (kg) & 1,5 & 0,4 \\
\hline Mật độ (câyha) & 12.000 & 12.000 \\
\hline Năng suất lý thuyết (tạa ha) & 21,6 & 19,7 \\
\hline Năng suất thực thu (tạ/ha) & 17,8 & 15,5 \\
\hline
\end{tabular}

Với mật độ 12.000 cây/ha và có chế độ chăm sóc như nhau. Nhưng Giống dưa vàng Kim Cô Nương có khối lượng quả trung bình là $1,5 \mathrm{~kg} /$ quả, cao hơn đối chứng $1,1 \mathrm{~kg}$ (bảng 5). Số quả/cây của giống dưa vàng Kim Cô Nương là 1.2 quả, ít hơn đối chứng 3,1 quả. Do giống dưa vàng Kim Cô Nương có khống chế về số lượng quả/dây, vì giống này khối lượng quả to hơn đối chứng.

Năng suất lý thuyết của giống dưa vàng Kim Cô Nương đạt 21,6 tạ/ha, cao hơn đối chứng không đáng kể 1,9 tạ. Năng suất thực thu của giống dưa vàng Kim Cô Nương đạt 17,8 tạ/ha, cao hơn đối chứng 2,3 tạ.

Bảng 5. Đặc điểm về quả

\begin{tabular}{|l|c|c|}
\hline Chì tiêu & Dưa vàng Kim Cô Nưrong & Dưa lê Thanh Đường \\
\hline Hình dạng quà (dạng) & Tròn ovan & Tròn \\
\hline Màu sắc quả (màu) & Vàng kim & Trắng xanh \\
\hline Độ Brix (\%) & 14,1 & 12,5 \\
\hline Hương thom (mùi) & Thơm & Thơm \\
\hline
\end{tabular}

Đặc điểm về hình dạng, màu sắc, chất lượng quả dưa có ảnh hưởng không nhỏ đến giá trị của giống dưa 
đó. Kết quả theo dõi (bảng 5) cho thấy, giống dưa vàng Kim Cô Nương có hình dạng tròn ovan, màu vàng kim. Quả đẹp, to và bắt mắt hơn giống đối chứng.

Độ Brix để đánh giá hàm lượng đường và có ý nghĩa đến chất lượng quả dưa, độ brix càng cao thì dưa càng ngọt. Giống dưa vàng Kim Cô Nương có độ brix là $14,1 \%$ và cao hơn đối chứng $1,6 \%$. Về hương thơm, giống dưa vàng Kim Cô Nương và đối chứng khi bổ ra đều có mùi thơm hấp dẫn.

Bảng 6. Hiệu quả kinh tế của giống dưa (ĐVT: Đồng/ha)

\begin{tabular}{|c|c|c|}
\hline Chỉ tiêu & $\begin{array}{c}\text { Dưa vàng Kim Cô } \\
\text { Nương }\end{array}$ & $\begin{array}{c}\text { Dưa lê Thanh } \\
\text { Đường }\end{array}$ \\
\hline Tổng thu & 356.000 .000 & 285.600000 \\
\hline Tổng chi & 118.550 .000 & 109.550 .000 \\
\hline Thu - chi & 237.450 .000 & 176.050 .000 \\
\hline
\end{tabular}

Hiệu quả kinh tế là chỉ tiêu quan trọng không những người trồng thử nghiệm mà cả người dân luôn quan tâm, bởi thể hiện kết quả của việc sản xuất có lãi hay không. Qua kết quả cho thấy, tổng thu của giống dưa vàng Kim Cô Nương đạt 356.000.000đ/ha, cao hơn giống đối chứng là 70.400.000đ. Do chủ yếu chênh lệch về giá bán, giống dưa vàng Kim Cô Nương có giá bán 20.000 đ/kg tại thời điểm thu hoạch và giá bán cao hơn giống đối chứng là 6.000 đ $/ \mathrm{kg}$. Tổng chi của giống dưa vàng Kim Cô Nương là 118.500 .000 đ/ha, chi nhiều hơn giống đối chứng là 9.000.000đ, do giá giống cao hơn giống đối chứng. Lợi ích kinh tế thu được từ việc trồng giống dưa vàng Kim Cô Nương là 237.450.000/ha, cao hơn giống đối chứng là 61.400 .000 đ.

\section{Kết luận và đề nghị}

\subsection{Kết luận}

Qua nghiên cứu trồng thử nghiệm giống dưa vàng Kim Cô Nương trên đất 2 vụ lúa tại Tuyên Quang, mặc dù thời gian sinh trưởng phát triển của giống dưa vàng Kim Cô Nương dài hơn giống đối chứng (6 ngày), sự sinh trưởng ở giai đoạn mọc và cây con còn chậm, khả năng chống chịu với một số loại sâu bệnh hại tương đương giống đối chứng dưa lê Thanh Đường. Năng suất thu của giống dưa vàng Kim Cô Nương là 17,8 tạ/ha và cao hơn đối chứng (2,3 tạ/ha). Dưa vàng Kim Cô Nương, giai đoạn thu hoạch có màu vàng, mã quả đẹp, hàm lượng Brix cao hơn và lợi ích kinh tế thu được lớn hơn (61.400.000đ/ha) so với trồng dưa lê Thanh Đường trên cùng một đơn vị diện tích và thời gian.

\section{2. Đề nghị}

Kết quả nghiên cứu bước đầu cho thấy những thuận lợi trong việc trồng và chăm sóc giống dưa vàng Kim Cô Nương tại khu vực thành phố Tuyên Quang và khẳng định tiềm năng về lợi ích kinh tế mà giống dưa này có thể mang lại nếu được đưa vào trồng sản xuất ở quy mô lớn hơn. Trong thời gian tới, tiếp tục trồng thử nghiệm trên các vùng khí hậu khác nhau trong tỉnh để hướng tới đưa giống dưa vàng Kim Cô Nương với lợi ích kinh tế tốt, phù hợp với điều kiện trồng trọt tại Tuyên Quang vào sản xuất thực tiễn, góp phần đa dạng hoá các sản phẩm nông nghiệp và nâng cao thu nhập cho người dân địa phương.

\section{TÀI LIỆU THAM KHẢO}

1. Trần Thị Ba, Trần Thiện Thiên Trang, Võ Thị Bích Thủy, 2009, So sánh sự sinh trương, năng suất và phẩm chất của 11 giống duva lê trong nhà luới vu xuân hè 2007, Tạp chí Khoa học số 11, trang 330-338, Trường Đại học Cần Thơ.

2. Đoàn Xuân Cảnh, Nguyễn Đình Thiều, Nguyễn Thị Thanh Hà, 2016, Kết quả nghiên cúu tuyển chọn giống cà chua, dura chuột, dura thơm thích hợp trồng trong nhà luới, nhà màn ở các tỉnh phía Bắc, Viện Khoa học Nông nghiệp Việt Nam, Hội nghị quốc gia về khoa học cây trồng lần thứ 2 "Nông nghiệp ứng dụng công nghệ cao và thích ứng với biến đổi khí hậu".

3. Đỗ Trung Hiếu, 2015, So sánh một số giống dua vàng và xác định một số biện pháp kỹ thuật trồng trọt cho giống dua uu tú, Trường Đại học Nông lâm Thái Nguyên.

4. Vũ Văn Liết, Hoàng Đăng Dũng, 2012, Đánh giá sinh truởng, phát triển và năng suất của một số giống dua lê nhập nội tù Trung Quốc tại Gia Lâm, Hà Nội, Tạp chí Khoa học và Phát triển, tập 10, số 2, trang 238243, Trường Đại học Nông nghiệp Hà Nội.

5. Châu Đăng Sơn, Kỹ thuật trồng dua lê Kim Cô Nuơng, Trung tâm Khuyến nông An Giang. 


\section{Research on trial planting of Kim Co Nuong yellow melon variety in Tuyen Quang province}

Nguyen Thi Minh Hue, Trinh Phuong Ngoc, Tran Thi Binh

\section{Article info}

Recieved:

16/11/2018

Accepted:

$10 / 12 / 2018$

Keywords:

Kim Co Nuong yellow melon; Tuyen Quang; evaluate growth and development; economic efficiency.

\begin{abstract}
In our country, Kim Co Nuong melon variety has been grown on short-term crop land in some provinces in the North, bringing higher productivity than rice and other crops. Kim Co Nuong yellow melon has good growth potential in Tuyen Quang; however, people are not broadly informed about it yet, and this type of melon has not been put into production. On that basis, Kim Co Nuong melon variety is studied and planted for trial on rice-growing land at the Demonstration practice and science - technology transfering centre, Tan Trao University, Tuyen Quang Province. Initial results show that the variety grows well and has higher yield of about 1.9-2.3 quintals, the economic efficiency is higher than 61.4 million VND / ha compared to the control variety- Thanh Duong melon variety which is currently grown locally on the same area and at the same time.
\end{abstract}

